\title{
Research on the Impact of Blockchain Technology on the Investment and Operation of the National Social Security Fund
}

\author{
Bin Liu" ${ }^{1,}$, Fangfang Dai ${ }^{2, b}$ \\ 1,2The college of Economics and Business administration \\ 1,2 Jiangxi Science and Technology Normal University, China nanchang \\ a908319865@qq.com, b1634866287@qq.com
}

Keywords: Blockchain technology; National social security fund; Investment operation

\begin{abstract}
With the improvement of living standard and the rapid development of economic globalization, China's population aging is becoming increasingly obvious, and the problem of population aging needs to be solved urgently. In the second digital revolution, block chain technology was applied to the social security fund in a "decentralized" technology mode. By analyzing the development process and characteristics of block chain technology, this paper deeply studied the impact of block chain technology on China's social security fund. Finally, several key factors in the application of block chain technology in the investment and operation of the national social security fund are proposed: technical factors, risk prevention and control, and cost management.
\end{abstract}

\section{Introduction}

Improvement of living standards, improving happiness index, and the rapid development of economic globalization, the aging trend of the population are becoming more and more obvious. Population over 60 years old in our country has risen from $10.46 \%$ in 2000 to $17.9 \%$ in 2018, and the pension rigid payment pressure is more and more big. Therefore, how to improve the national social security fund (hereinafter referred to as the national social security fund) investment operation efficiency, improve value preserving and appreciation determine, prevent and resist the payment risk which may appear at any time are very important to. In recent years, the introduction of block chain and other modern technologies has not only changed people's lifestyle, but also provided new tools for the reform of finance, insurance and other fields. In July 2018, the Chinese social security association launched the application research of block chain in the field of social security, marking that the integration of block chain technology and social security fund will become a new trend of research.

\section{The connotation and analysis of block chain}

\subsection{Literature review}

Block chain technology was first used in BTC during the economic crisis in 2008. Satoshi Nakamoto, a Japanese-American, he published his article describing an electronic currency he calls "BTC" and its algorithms on the website. With the rapid development of technology, the application of block chain technology has gradually shifted from the single BTC field to other fields, such as supply chain finance, insurance, industry and other aspects. Since 2015, the academic focus has shifted from BTC to block chain technology. Since BTC is a virtual currency and cannot replace real money, the academic community is more inclined to focus on block chain technology in fields other than BTC. In some ways, the block chain revolution has only just begun. Mei haitao and Jie Liu (2016) published their own opinions, believed that the essence of block chain technology is a way to collectively maintain a reliable database through decentralization and trust.

Wang xueying (2018) believed that block chain technology can promote the development and system improvement of China's Banks and financial institutions. Hu qilin (2019) believed that the application of block chain technology is still in its infancy, and block chain has the characteristics of decentralization, trusted interactive technology, intelligent contract, coordination and sharing 
mechanism, marketization and digitization, and currency timestamp, and promotes the formation of "block chain + finance" mode.

At present, the application of global block chain in the financial field ranks the first, followed by information and communications, the underlying technology and infrastructure, cultural and other segmentation scenario, There is little academic discussion on the theme of "block chain + national social security fund", it was not find on CNKI, but as part of the national social security fund investment sector, it deserves attention.

\subsection{The connotation and characteristics of block chain}

Block chain technology is a technology to maintain a database according to a certain time sequence of records. It has open source, distributed, decentralized, high stability and trust, transactions anonymous and transparent and other characteristics.

\section{Block chain technology on the national social security fund investment}

In 2001, the state council approved the "interim measures for the national social security fund investment management", The investment scope of the fund has been stipulated in the document: limited to bank deposits, bonds and other liquid financial instruments, securities investment fund is the file also at the same time, and the proportion of stock investments shall not exceed forty percent, so the capital market investment income level will directly affect the national social security fund size.

\subsection{The development of capital market is closely related to technological innovation}

The development of capital market is closely related to the innovation of science and technology. Both the financial revolution and the industrial and technological revolution are accompanied by each other. The first industrial revolution (1765-1850) produced the steam engine, which injected power into the capital output of the first industrial revolution in Britain by establishing the central bank and commercial banking system. The second industrial revolution (1866-1900) saw the widespread application of electricity and the invention of internal combustion engine. With the rapid development of European and American countries, some companies represented by Morgan, Rockefeller and others gradually formed, and gradually established a mature investment banking system. The third scientific and technological revolution (1940-1990) began with the application of electronic computers, thus driving the germination of venture capital. In the first digital revolution (1990-2010), Internet finance, relying on the mature information Internet, subverted the expression mode and means of financial activities. In the second digital revolution (2010-2025), the goal of decentralization and disintermediation will be achieved through the block chain technology and the value Internet.

\subsection{Block chain technology to strengthen the national social security fund investment supervision}

\subsubsection{Block chain technology has solved the integrity problem of social security fund managers}

The national social security fund is divided into direct investment operation (such as primary market bond underwriting) and entrusted investment management (such as stocks, corporate bonds, etc.). Since 2002, the national social security fund has entrusted fund companies with investment. According to data from the national council for social security fund, the total assets of social security fund reached 2.22 trillion yuan at the end of 2017. Among them, the total amount of direct investment is 0.94017 trillion yuan, accounting for $42.35 \%$; Total indirect investment was 1.27983 trillion yuan, accounting for 57.65 percent. Therefore, investment integrity is a huge social security fund asset management is a crucial factor.

Since 2002, nanfang, boshi, huaxia, penghua, changsheng and harvest have been the national social security fund managers, and bank of China and bank of communications have been the fund custodians. Block chain technology can set up monitoring nodes and increase business credit through consensus agreement and programmable intelligent contract, and stop any violation of contract principle in the implementation of investment by fund companies in time. 


\subsubsection{Block chain technology solves the privacy problem of investment information}

With the development of block chain technology, the production and dissemination of information are more and more extensive, and proprietary information ownership is more and more difficult to identify. Investment information is one of the many information flows. The release of false investment information affects the national social security fund investment benefits. In the distributed database system of block chain, the form of time stamp is constructed to form traceable, verifiable and tamper-resistant data based on information block and data chain, so as to solve the problem of originality and ownership of information and strengthen the privacy of investment information.

\subsection{Block chain technology into the national social security fund portfolio}

According to Markowitz, professor of modern portfolio theory, the national social security fund investment portfolio with both high security low-yielding bank deposits, trust loans and other assets, and there was a high-risk high-yield equity investment, foreign assets such as stocks, they produce higher yields. From $6.79 \%$ in 2008 rise to $9.68 \%$ in 2017, far more than the same period bank's oneyear deposit rate $(1.5 \%)$. by the end of 2017 , the national social security fund investment trading financial assets to total assets ratio is $39.3 \%$, held-to-maturity bonds is $35.79 \%{ }^{1}$

In order to diversify investment risks, NSSF has set up 59 portfolios, of which 52 are managed by 9 fund companies respectively ${ }^{2}$. Boshi manages the 108 portfolio of the national social security fund, a well-known fund in the capital markets, which is well-known in the capital market. As of March 31, 2019, the 108 portfolio of the national social security fund holds 22 stocks, including Yifan pharmaceutical, Yonggui electric appliance, Oriental A, Great Wall of China, changdian technology, wentai technology and weitong, among which the outstanding shares of weitong company account for 2.01 percent, making it the fourth largest shareholder.

The national social security fund has been paying attention to block chain technology since 2016, and it is ready to use it in payment of pension and career allowances. Meanwhile, the fund investment portfolio is also gradually tending to the high-tech listed companies led by block chain. Weitong, a company invested by the 108 portfolio of the national social security fund, owns a security cloud that meets the requirements of password application and is a block chain technology concept company, which is also favored by the national social security fund. Its shareholding ratio increased from $1.448 \%$ in 2018 to $2.01 \%$, indicating the confidence of the national social security fund in the development and use of block chain technology.

\section{Block chain technology application in the national social security fund investment and operation of key factors}

Block chain technology has been increasingly developed in the financial field, but it is still too early to apply in the national social security fund investment. Different from other market funds, NSSF investment has the goal of "maintaining and increasing value" when it enters the market. How to strengthen the supporting role of block chain technology in social security fund investment and change the constraints in operation are the key to improve the application of block chain technology.

\subsection{Technical factors}

Participants. With the frequent financial trade in China, a large number of investment and financing and international settlement have generated a large amount of data, especially the national social security fund investment involves a wide range of fields, investment objects switch quickly, put forward high technical requirements for the block chain system capacity and processing speed. If each block chain is an independent decentralized body, the capacity is limited and the processing speed is relatively slow, and the participants may not have time to integrate into the system process.

\footnotetext{
${ }^{1}$ Over the past 18 years, I have earned 1 trillion yuan -- an investment from the social security fund https://baijiahao.baidu.com/s?id=1611906275686557725\&wfr=spider\&for=pc

${ }^{2}$ Xiaoyue heshen: turn: decrypt the social security fund portfolio. Snowball, https://xueqiu.com/9850490771/114535982
} 
Security. According to the nature of block chain, only when more than $50 \%$ of nodes are controlled can data be modified or tampered with. Therefore, it is expensive to launch an attack, but it is not impossible. Especially in fund investment, customers and private information may be tampered or leaked, which will affect the effect of investment operation.

\subsection{The risk prevention and control}

The integration of block chain technology and national social security fund requires the integration of information technology supervision and financial system supervision. The decentralized, automatic management and common maintenance characteristics of block chain will affect the investment operation framework, scope and regulatory laws and systems of the national social security fund, which need to be guaranteed by relevant laws; On the other hand, once virtual currency enters the investment field, whether its value is supported by real money and real economy, and the analysis of stable investment and operation are still under discussion

\subsection{Cost management}

In order to apply block chain technology in the national social security investment and operation, it is necessary to invest a large amount of manpower, financial and material resources to update and transform hardware equipment, software and regulatory environment, control the application cost, and effectively link up various subjects in line with regulatory requirements.

\section{Summary}

This paper analyzes the development process and characteristics of block chain technology, and deeply studies the impact of block chain technology on China's social security fund. At the same time, it emphasizes the important role of block chain technology in the supervision of the investment of the national social security fund. Finally, several key factors of application of block chain technology in the investment and operation of the national social security fund are proposed: technical factors, risk prevention and control, and cost management.

\section{References}

[1] wang xueying. Discussion on the influence and opportunities of "block chain" technology on traditional financial behavior [J]. Times finance.2018 (10): 35-37.

[2] hu qilei. Application research of block chain technology in the financial field -- based on the perspective of "One Belt And One Road" [J]. Friends of accounting. 2019(5):151-156.

[3] Mei Haitao, Liu Jie. Industry Status, Existing Problems and Policy Suggestions of Block chain [J]. Telecommunications Science and Technology, 2016(11): 134-138.

[4] shang fang. The value of "chain" connecting social security [J]. China social security,2018(08):18-19. 